\title{
EFFECT OF IMMEDIATE AND DELAYED POST SPACE PREPARATION ON THE APICAL SEAL OF ROOT CANALS OBTURATED WITH DIFFERENT SEALERS AND TECHNIQUES
}

\author{
Hikmet AYDEMIR ${ }^{1}$, Gözlem CEYLAN² ${ }^{2}$ Tamer TASDEMIR ${ }^{3}$, Elif KALYONCUOGLU ${ }^{4}$, Ibrahim ISILDAK ${ }^{5}$
}

1- DDS, PhD, Associate Professor, Department of Endodontics, Faculty of Dentistry, Ondokuz Mayis University, Samsun, Turkey.

2- DDS, PhD, Associate Professor, Department of Prosthodontics, Faculty of Dentistry, Ondokuz Mayis University, Samsun, Turkey.

3- DDS, Assistant Professor, Department of Endodontics, Faculty of Dentistry, Karadeniz Technical University, Trabzon, Turkey.

4- DDS, Research Assistant, Department of Endodontics, Faculty of Dentistry, Ondokuz Mayis University, Samsun, Turkey.

5- DDS, PhD, Associate Professor, Department of Chemistry, Faculty of Dentistry, Ondokuz Mayis University, Samsun, Turkey.

Corresponding address: Dr. Hikmet Aydemir - Ondokuz Mayis University, Faculty of Dentistry, Department of Endodontics - 55139, Samsun, Turkey Fax: +0 3624576032 - e-mail: haydemir@omu.edu.tr; gceylan@omu.edu.tr

Received: December 17, 2008 - Modification: July 08, 2009 - Accepted: July 09, 2009

\begin{abstract}
$D$

uring mechanical preparation of the post space, the root canal filling may be twisted or vibrated, depending on several factors associated with the preparation technique and quality of filling. Objective: The purpose of this study was to investigate the effect of immediate and delayed post space preparation on the integrity of the apical seal. Material and Methods: Sixty-four extracted human incisors were biomechanically prepared using the step-back technique. Sixty roots were randomly assigned to 6 experimental groups of 10 teeth each and the remaining 4 roots served as positive and negative controls $(n=2)$. The root canals in the different groups were obturated with cold lateral and warm vertical condensation of gutta-percha and one of two sealers (Sealapex and Diaket). Post space was prepared either individually or simultaneously. An insulated copper wire was cut into 10-cm-long pieces. In each canal, one piece was inserted to maintain contact with gutta-percha and extended to the outside as one of two working electrodes. A stainless steel wire with the same dimensions of those of the copper wire, used as the other working electrode, was immersed into the background electrolyte from the center of the bottle. The electrical current between standard and experimental electrodes in canals was measured over a period of 10 days applying a conductivity meter. The Kruskal-Wallis test $(p=0.05)$ determined whether there was a significant difference in microleakage among the groups and the Mann-Whitney $U$ test $(p=0.01)$ was used for multiple comparison grouping variables. Results: The results suggest that only the differences between the root canal filling techniques were statistically significant $(\mathrm{p}<0.01)$. There were no statistically significant difference in the sealers and the times of filling removal for post space preparation $(\mathrm{p}>0.01)$. Conclusion: The quality of the root canal filling is important for the integrity of the apical seal.
\end{abstract}

Keywords: Post space preparation. Apical microleakage. Electrochemical study.

\section{INTRODUCTION}

Endodontically treated teeth often lack sufficient support for a permanent restoration. An additional retention can be necessary gained from the root canal ${ }^{5,7,13}$. Thus, these teeth often may require the use of an intracanal post for retention of the core ${ }^{5-7,25,26}$. The post fits into a space created by the removal of a portion of filling material and this procedure may affect the quality of the apical seal ${ }^{6,7}$. During mechanical preparation of the post space, the root canal filling material may be dislodged creating voids in the obturation ${ }^{6}$, and the filling material may be twisted or vibrated. Several factors can affect the integrity of the apical seal ${ }^{7,14}$ while post space is prepared, such as length of gutta-percha to maintain the apical seal $1^{7,20.21}$ time of removal of the filling material $1^{3,7,8,15,19,22,26,29}$ and method of gutta-percha removal ${ }^{3,8,11,12,19,27,30}$. Furthermore, few studies have investigated the leakage of endodontic obturation techniques and materials related to post preparation and the effect of post space preparation on the integrity of the apical seal of teeth obturated initially by different material and obturation technique ${ }^{6,9,23,29}$. Grive and Radford ${ }^{9}(1995)$ have suggested that root canal preparation for the placement of a post may cause displacement of remaining filling material, when this material is insufficient or not correctly condensed.

The purpose of this study was to investigate the effect of immediate and delayed post space preparation on the integrity of the apical seal of root canals obturated with two 
commonly used root canal sealers each having different properties and root canal filling techniques using an electrochemical method.

\section{MATERIAL AND METHODS}

Sixty-four recently extracted human maxillary incisors of approximately equal size with single root canals and mature apices were selected for this study. All teeth were stored in ionized water with thymol and were immersed in $5.25 \%$ sodium hypocholorite $(\mathrm{NaOCl})$ for $8 \mathrm{~h}$ to remove surface-adhered organic material. The teeth were decoronated at the cementoenamel junction using watercooled high-speed fissure bur (Prodottoda; Diamir Srl Loc., Resia, Italia).

The canal lengths were measured by placing a size 15 K-file (Kerr/Sybron, Romulus, MI, USA) into each root canal until the tip of the file was visible at the tip of the apical foramen. The working length was established $1 \mathrm{~mm}$ short of the apex. Root canals were instrumented at the working length with a size $50 \mathrm{~K}$-file (Kerr/Sybron) using a step-back technique. Then, root canals were prepared from crown to apex using sizes 1 to 4 Gates Glidden drills (Maný, Inc. Takznezawa-Machi Sioya-gun, Tochigi-kan, Japan). The roots were irrigated with $10 \mathrm{~mL}$ of $5.25 \% \mathrm{NaOCl}$, and then dried with paper points (Meta Dental Co. Ltd. Korea). Sixty roots were randomly assigned to 6 experimental groups of 10 teeth each and the remaining 4 roots were used as positive and negative controls of two specimens each. The canal sealers were mixed and handled according to the manufacturers' instructions.

Group 1: The canals were filled with cold lateral condensation of gutta-percha (Dia Dent Group International Inc., Korea) and a calcium hydroxide-based sealer (Sealapex; Kerr/Sybron). Post space was prepared 30 days after root canal obturation (AH26, Sealapex, and Tubuliseal were partially set after 1 week and set was complete after 4 weeks ${ }^{1}$ ), using size 4 Gates-Glidden drill and leaving $5 \mathrm{~mm}$ of remaining filling.

Group 2: Root canal filling and post space preparation were done in the same manner as described for group 1, except for the fact the post space was created 40 min after obturation (Sealapex with a bench setting time of $40 \mathrm{~min}$ become commercially available $\left.{ }^{18}\right)$.

Group 3: Root canal filling and post space preparation were done in the same manner as described for group 1, except for the fact that a resin-based sealer (Diaket; ESPE, Seefeld, Germany) was used.

Group 4: Root canal filling and post space preparation were done in the same manner as described for group 3, except for the fact the post space was created 40 min after obturation.

Group 5: Root canal filling and post space preparation were done in the same manner as described for group 3 , except for the fact that the warm vertical condensation technique was used.

Group 6: Root canal filling and post space preparation were done in the same manner as described for group 1, except for the fact that the warm vertical condensation technique was used.

In warm vertical condensation technique, due to the direct placement to the apical portion of root canal filling and because further post space preparation is unnecessary, experimental groups of immediate post space preparation were not designed.

Radiographs were taken to confirm the quality of root canal obturation using a dental $\mathrm{x}$-ray equipment set at 70 
Kvp and 8 mA (Trophy-ETX, CG 320; Trophy Radiologie, Vincennes, Cedex, France). After filling and post preparation were completed, the surfaces and coronal openings of all roots were coated with two layers of sticky wax (Cavex Set Up Regular Cavex Holland BV, RW Hearlem, The Netherlands), except for the apical $2 \mathrm{~mm}$. Between phases of the experiment, the specimens were stored in $100 \%$ humidity.

The specimens used as positive and negative controls were instrumented and the two positive control roots were filled with a loosely fitted gutta-percha cone without endodontic sealer and the two negative controls were not obturated. The apical foramen of the positive control was completely covered with two layer of sticky wax, except for the apical $2 \mathrm{~mm}$, whereas that of the negative control was completely covered with two layer of sticky wax.

An insulated 1-mm-diameter copper wire (Alcatel, Turkey) was cut into 10 -mm long pieces. In each canal, one piece was inserted to maintain contact with gutta-percha (5 $\mathrm{mm}$ from the apical foramen, as confirmed radiographically), and extended to the outside, acting as one of two working electrodes. The specimens were secured in place by sticky wax. A 1-mm-diameter stainless steel wire (Alcatel, Turkey) was also cut into $10-\mathrm{mm}$ long pieces, which were used as the other working electrode, being immersed into the background electrolyte from the center of the bottle. A $1.0 \%$ $\mathrm{NaCl}$ solution as the background electrolyte was placed in the bottle until the apical half of the roots was submerged.

The electrical current between standard and experimental electrodes in canals was measured over a period of 10 days applying a conductivity meter (Cmd $750 \mathrm{Wpa} /$ Linton Cambridge-UK). On the first day, the electrical conductivity was measured at baseline and then $2,12,24,36,48,72,96$, 120 and $240 \mathrm{~h}$. In addition, for each group, the electrical conductivity was measured by applying $50 \mathrm{~Hz} 44 \mathrm{~V}$ electrical current constent for $10 \mathrm{~s}$ with a multimeter (Thurlby 1503; Thandar Ltd., 2 Gelebe Rd, Huntingdan, Cambs, Pe18,7Dx, England) after 10 days.

The Kruskal-Wallis $(p=0.05)$ test was applied to the results to determine whether there was a significant difference in microleakage among the groups, and the MannWhitney $U$ test $(p=0.01)$ was used for multiple comparison of grouping variables.

\section{RESULTS}

Table 1 shows the mean apical leakage (in microsiemens) and standard deviations of the experimental and control groups with time. Table 2 shows the variation of apical leakage at the time intervals according to the sealer, filling technique and time of filling removal.

There were statistically significant differences among the groups $(p<0.05)$. The results suggest that there was a significant difference between the root canal filling techniques $(\mathrm{p}<0.01)$. There were no significant difference $(p>0.01)$ between the sealers and the times of filling removal for post space preparation (delayed versus immediate).

TABLE 2- Mean apical leakage (micro-siemens) and standard deviations(SD) at the time intervals according to the sealer, filling technique and time of filling removal

\begin{tabular}{|c|c|c|c|c|c|c|c|c|c|c|c|c|}
\hline \multirow[t]{2}{*}{ Grouping variables } & & \multicolumn{11}{|c|}{ Time interval (hours) } \\
\hline & & 0 & 2 & 12 & 24 & 36 & 48 & 72 & 96 & 120 & 240 & 240/EC* \\
\hline \multicolumn{13}{|l|}{ Sealer } \\
\hline \multirow[t]{2}{*}{ Sealapex } & Mean & 0.16 & 0.63 & 16.51 & 26.01 & 38.44 & 39.55 & 47.71 & 52.03 & 53.17 & 54.33 & 69.01 \\
\hline & SD & 0.27 & 0.38 & 19.45 & 28.36 & 44.44 & 45.76 & 48.45 & 54.71 & 54.64 & 54.27 & 89.35 \\
\hline \multirow[t]{2}{*}{ Diaket } & Mean & 0.42 & 3.29 & 14.85 & 23.18 & 29.36 & 26.87 & 33.04 & 34.53 & 39.06 & 40.35 & 41.63 \\
\hline & SD & 0.61 & 4.30 & 30.34 & 39.30 & 49.40 & 44.17 & 51.44 & 55.19 & 60.78 & 62.32 & 63.14 \\
\hline \multicolumn{13}{|l|}{ Filling technique } \\
\hline \multirow[t]{2}{*}{ Cold lat. cond. } & Mean & 0.41 & 2.74 & 23.36 & 36.37 & 50.05 & 48.93 & 59.44 & 64.02 & 67.89 & 69.44 & 81.19 \\
\hline & SD & 0.55 & 3.83 & 28.02 & 36.36 & 50.09 & 48.02 & 51.68 & 57.24 & 59.80 & 60.33 & 84.37 \\
\hline \multirow[t]{2}{*}{ Warm vert. cond. } & Mean & 0.05 & 0.40 & 0.32 & 1.06 & 1.60 & 1.77 & 2.25 & 1.81 & 2.57 & 3.14 & 3.59 \\
\hline & SD & 0.08 & 0.31 & 0.42 & 1.89 & 2.65 & 2.64 & 3.56 & 3.60 & 4.41 & 4.86 & 5.13 \\
\hline \multicolumn{13}{|l|}{ Time of filling removal } \\
\hline \multirow[t]{2}{*}{ Immediate } & Mean & 0.37 & 2.94 & 16.63 & 25.54 & 31.18 & 32.04 & 38.74 & 40.11 & 42.43 & 43.71 & 45.92 \\
\hline & SD & 0.68 & 4.77 & 19.71 & 23.65 & 28.73 & 29.16 & 32.83 & 35.54 & 34.98 & 35.68 & 36.93 \\
\hline \multirow[t]{2}{*}{ Delayed } & Mean & 0.25 & 1.47 & 15.21 & 24.13 & 35.26 & 33.80 & 41.20 & 44.87 & 47.96 & 49.15 & 60.02 \\
\hline & SD & 0.34 & 2.18 & 27.87 & 38.43 & 53.91 & 51.52 & 57.17 & 63.18 & 66.61 & 67.25 & 91.96 \\
\hline
\end{tabular}

* EC= Electrical current $(50 \mathrm{~Hz} .44 \mathrm{mV})$. 


\section{DISCUSSION}

The restoration of endodontically treated teeth often requires intracanal post retention ${ }^{6,7}$. In order to create space for post, some filling material is removed from the canal, and during the preparation of this space, the root filling material may be dislodged by reason of creating voids in the obturation ${ }^{14}$. Several studies have shown that the integrity of the reaming obturation after removal of root canal filling materials may be depend on a number of factors, and some of these factors are techniques and instruments used for removal $3,8,11,12,19,27,30$ the length of the remaining materials $^{20,21,25}$, endodontic obturation techniques ${ }^{6,8,9,23}$, used cements and time of their setting ${ }^{1,15,18,24,26}$ and time of removal of root filling 3 $^{3,7,8,15,19,22,24,26,29}$.

In the present in vitro investigation, the effect of the guttapercha removal on the apical seal was evaluated, and various depths ${ }^{7,21}$ and techniques ${ }^{8,11,28,30}$ were recommended for the preparation of a post space. Several studies ${ }^{8,12,19,27}$ have reported that no statistical difference in apical leakage could be observed before or after post preparation with various techniques. Also, Hiltner, et al. ${ }^{12}$ (1992) reported no significant difference in leakage when comparing guttapercha removal using flame-heated endodontic Plugger, Peeso reamer, GPX burs, and Touch'n heat electrically heated spreader. However, Mattison, et al. ${ }^{21}$ (1984) found little difference between mechanical removal with Gates Glidden burs and removal with a hot plugger. Haddix, et al. ${ }^{11}$ (1990) found that removal with a warm plugger produced the least leakage. In the present study, rotary instrumentation was used to remove gutta-percha because it is a faster, easier and commonly performed method of creating post space $^{13}$.

In the studies investigating the minimum amount of obturation material that must remain ${ }^{20.21,25}$ to avoid disruption of the apical seal in post space preparation, it is widely accepted that $5 \mathrm{~mm}$ of root canal filling should be left in the apical. In our study, in the apical section of the canal was remained at least $5 \mathrm{~mm}$ of root canal filling in conformity with studies ${ }^{20.21}$.

Several studies have investigated the leakage of endodontic obturation techniques and materials related to post preparation ${ }^{6,9,23}$. Grive and Radford ${ }^{9}$ (1995) have suggested that root canal preparation for the placement of a post may cause displacement of the remaining filling material, when this material is insufficient or not correctly condensed. In his study, Neagly ${ }^{23}$ (1969) found that the apical seal was not significantly affected by the use of rotary instruments regardless of the type of filling material used, when the canals had been adequately obturated.

Different materials and methods are available for root canal obturation. Many obturation techniques have been developed to minimize gap formation along the root canal and specifically to increase the quality of the apical seal ${ }^{17}$. It is generally agreed that the use of gutta-percha cones with a sealer is one of the most reliable methods for filling the root canal system ${ }^{26}$. Currently, lateral condensation is widely used due to its acceptable long-term results, predictability controlled placement and relative ease of use ${ }^{16}$. However, this technique produces many irregularities in the final mass of gutta-percha, and might not fill canal fins, cul-de-sacs and isthmuses. There is also inadequate dispersion of sealer, leaving voids in and around the gutta-percha cones ${ }^{16}$. Thus, a number of different plasticized gutta-percha techniques have been introduced with the aim of securing better sealing of the canal irregularities ${ }^{17}$ In this study the effect of immediate and delayed post space preparation on the integrity of the apical seal of the root canals obturated initially by commonly used the laterally condensed and warm vertical condensed of gutta-percha techniques was searched. The post space preparation probably caused the loss of apical integrity of the lateral condensation group, and differences in microleakage between techniques were found statistically significant.

The usual canal filling material is gutta-percha in conjunction with a sealer. Gutta-percha has no adhesive qualities or adaptability to dentin of the root canal wall, so it must be used in combination with sealer. If leakage occurs, it can take place at either the gutta-percha/sealer interface or the sealer/dentin wall interface ${ }^{4,26}$. Therefore, some of the physical properties of the sealer and the possible effect of a post preparation on the sealer become important ${ }^{15,26}$. Root canal sealers serve to fill voids and minor discrepancies of fit between the gutta-percha filling and root canal wall ${ }^{4,18}$. Grosman ${ }^{10}$ (1976) studied the physical properties of sealers (e.g.: flow, setting time. shrinkage, etc.) and postulated that sealing ability may be related to those physical properties and that manipulation of the material during or after filling could affect the ability to produce a good seal. Therefore, some of the physical properties of the sealer and the possible effect of a post preparation on the sealer become important. Not only an endodontic sealer should help creating a root filling that seals the canal system effectively, but it must also allow the removal of the gutta-percha. For this reason, the ability of a sealer to bond to the tooth structure is of considerable importance ${ }^{26}$. Adhesion to dentin and the lack of tensile strength of some of sealers probably creates gaps and voids caused by crumbling of the set material ${ }^{15}$. Therefore, two different sealers were evaluated in the present study, but there were no significant differences in leakage between them.

The electrochemical method used in the present study appears to be the most objective way to measure leakage in the canal. It is easily comparable and analyzed, and provides the opportunity to study leakage in a continuous time period, with the advantage of being able to record the time when maximum leakage occurs ${ }^{20}$.

Another important question in post space preparation is: Is it best to prepare post space at the time of canal obturation or wait until the sealer has set ${ }^{29}$ ? These steps may be performed individually or simultaneously, and there is no consensus on the time interval between the endodontic treatment and post preparation; while some authors indicate an immediate preparation ${ }^{26,29}$, others recommend different time intervals ${ }^{8,15}$. Before complete sealer setting is achieved, it is possible that the root filling become twisted or vibrate 
during mechanical post space preparation, in such a way to cause disruption of the apical seal ${ }^{14}$. According to Morgano, et al. ${ }^{22}$ (1994), in the restoration of endodontically treated teeth, space for any posts required should be gained with rotary instruments at a subsequent visit after the complete setting of the sealer, and that the apical segment of the root filling can be condensed after the coronal gutta-percha has been removed. On the other hand, Bishop and Briggs ${ }^{2}$ (1995) stated the need for restoration immediately following completion of endodontic treatment in order to protect the treated tooth from microbial contamination. In addition, those authors stated that, at this time, the clinician is most familiar with the canal system anatomy and reference points.

Comparing delayed $(>24 \mathrm{~h})$ versus immediate removal of gutta-percha, two studies ${ }^{19}$ found little or no difference on the apical seal, while another study ${ }^{17}$ found less leakage when immediate removal of gutta-percha was done. In the present study, delayed removal of gutta-percha for post space preparation produced numerically better results in apical leakage, but without statistical significance compared to immediate preparation. The quality of the existing obturation can effect the apical seal during post space preparation. For this reason, the selection of the obturation technique is important for teeth to be restored with intraradicular post. The warm vertical condensation technique should be prefered when the post space preparation is made, and care should be taken to avoid any distruption to the integrity of the apical seal while the post space is being prepared. If any doubt exists about the quality of the root filling before or after post space preparation, a new root canal filling should be placed.

\section{CONCLUSION}

Under the tested conditions, the following conclusions can be drawn: 1. The quality of the root canal filling is important to maintain the integrity of the apical seal during post space preparation. According to the results, warm vertical condensation filling technique is better than cold lateral condensation filling technique to avoid disruption of apical seal integrity; 2. No significant difference was found between the sealers regarding the integrity of apical seal during post space preparation; 3. Immediate and delayed post space preparation produced similar results.

\section{REFERENCES}

1- Allan NA, Walton ER, Schaffer M. Setting times for endodontic sealers under clinical usage and in-vitro conditions. J Endod. 2001;27(6):421-3.

2- Bishop K, Briggs P. Endodontic failure: a problem from top to bottom. Br Dent J. 1995;179:35-6.

3- Bourgeois RS, Lemon RL. Dowel space preparation and apical leakage. J Endod. 1981;7:66-9.

4- Caicedo R, von Fraunhofer JA. The properties of endodontic sealer cements. J Endod. 1988;14(11):527-34
5- Cheung W. A review of the management of endodontically treated teeth : Post, core and the final restoration. J Am Dent Assoc. 2005;136:611-9.

6- Dalat DM, Spangberg LSW. Effect of post preparation on the apical seal of teeth obturated with plastic thermafil obturators. Oral Surg Oral Med Oral Pathol. 1993;76:760-5.

7- De Cleen MJH. The relationship between the root canal filling and post space preparation. Int Endod J. 1993;26:53-8.

8- Ewart A, Saunders WP. An investigation into the apical leakage of root-filled teeth prepared for a post crown. Int Endod J. 1990;23(5):23944.

9- Grieve AR, Radford JR. Radiographic observations of post crowns: some problems and solutions. Dent Update. 1995;22(9):370-2.

10- Grossman L. Physical properties of root canal cements. J Endod. 1976;2:166-75.

11- Haddix JE, Mattison GD, Shulman CA, Pink FE. Post preparation techniques and their effect on the apical seal. J Prosthet Dent. 1990;64(5):515-9.

12- Hiltner RS, Kulild JC, Weller RN. Effect of mechanical versus thermal removal of gutta-percha on the quality of the apical seal following post space preparation. J Endod. 1992;18:451-4.

13- Hunter AJ, Flood AM. The restoration of endodontically treated teeth. Part 1. Treatment planning and restorative principles. Aust Dent J. 1988;33:481-90.

14- Jeffrey IWM, Saunders WP. An investigation into the bond strength between a root canal sealer and root-filling points. Int Endod J. 1987;20;217-22.

15- Karapanou V, Vera J, Cabrera P, White RR, Goldman M. Effect of immediate and delayed post preparation on apical dye leakage using two different sealers. J Endod. 1996;22(11):583-5.

16- Kertsen H, Fransman R, Velzen TVS. Thermomechanical compaction of gutta-percha. A comparison with lateral condensation in curved root canals. Int Endod J. 1986;19:134-40.

17- Kqiku L, Weiglein A, Stadtler P. A comparative study of five different obturation techniques. Acta Stomat Croat. 2006;40(1):3-11.

18- Lim KC,Brian GT. The sealing ability of Sealapex compared with AH26. J Endod. 1986;12(12):564-6.

19- Madison S, Zakariasen KL. Linear and volumetric analysis of apical leakage in teeth prepared for posts. J Endod. 1984;10:422-7.

20- Mattison GD, von Fraunhofer JA. Electrochemical microleakage study of Endodontic sealer cements. Oral Surg Oral Med Oral Pathol. $1983 ; 55: 402-7$.

21- Mattison GD, Delivanis PD, Thacker RW, Hassell KJ. Effect of post preparation on the apical seal. J Prosthet Dent. 1984;51(6):785-9.

22- Morgano SM, Hashem AF, Fotoohi K, Rose L. A nationwide survey of contemporary philosophies and techniques of restoring endodontically treated teeth. J Prosthet Dent. 1994;72:259-67.

23- Neagley RL. The effect of dowel preparation on the apical seal of endodontically treated teeth. Oral Surg Oral Med Oral Pathol. 1969;28:739-45.

24- Pesce ALC, Lopez SG, Rodriguez MPG. Effect of post space preparation on apical seal: Influence of time interval and sealer. Med Oral Patol Oral Cir Bucal. 2007;12(6):E464-8. 
25- Ricci ER, Kessler JR. Apical seal of teeth obturated by the laterally condensed gutta-percha, the thermafil plastic and thermafil metal obturator techniques after post space preparation. J Endod. 1994;20:123-6.

26- Saunders EM, Saunders WP, Rashid MYA. The effect of post space preparation on the apical seal of root fillings using chemically adhesive materials. Int Endod J. 1991;24:51-7.

27- Saunders WP, Saunders EM, Gutmann JL, Gutmann ML. An assessment of the plastic Thermafil obturation technique. Part 3: the effect of post space preparation on the apical seal. Int Endod J. 1993;26:184-9.

28-Sidhu VK, Thakore AJ, Banga KS. Evaluation of post space preparation and its effect on the apical seal: an in vitro study. Endodontology. 1998;10(2):44-9.

29- Solano F, Hartwell G, Appelstein C. Comparison of apical leakage between immediate versus delayed post space preparation using $\mathrm{AH}$ plus sealer. J Endod. 2005;31(10):752-4.

30- Zmener O. Effect of dowel preparation on the apical seal of endodontically treated teeth. J Endod. 1980;6:687-90. 